\title{
Analysis of imprinted genes in subjects with Prader- Willi syndrome and chromosome 15 abnormalities
}

Bethi Muralidhar, PhD, Annis Marney, BA, and Merlin G. Butler, $M D, P h D$

\begin{abstract}
Purpose: To determine gene expression of five imprinted genes or transcripts from the 15q11-q13 chromosome region using reverse transcription polymerase chain reaction (RT-PCR) in a relatively large survey of Prader-Willi syndrome (PWS) and control subjects with several different chromosome 15 abnormalities. Methods: RT-PCR was undertaken on mRNA isolated from tissue (e.g., mostly lymphoblasts) from 38 PWS and 10 control subjects. DNA primers were used for five imprinted genes or transcripts (ZNF127, SNRPN, PAR5, IPW, and PAR1) from 15q11-q13 and fibrillin, a control gene from 15q21. Results: One PWS subject with maternal disomy 15 showed weak but detectable expression of PAR1, whereas SNRPN expression was detected in two PWS subjects [one with the 15q11-q13 deletion and one with a t(15;15) karyotype and maternal disomy 15], and the remaining typical PWS subjects showed no expression of the imprinted genes or transcripts. Conclusion: No obvious clinical differences were identified in those PWS subjects with weak expression of genes compared with those showing no expression. Although the reason(s) for weak expression is unknown, possible explanations include relaxation of imprinting caused by failure to reset the imprinted genes or transcripts in the maternal germ line or by postzygotic gene expression or undetected chromosome 15 mosaicism in the deletion PWS subjects. The timing, tissue source, and other factors relating to partial expression of genes that are thought to be imprinted may play a role in clinical variability and allow for a better understanding of molecular mechanisms in PWS and other abnormalities of proximal chromosome 15q. Genetics in Medicine, 1999:1(4):141-145.
\end{abstract}

Key words: chromosome 15q11-q13 region, gene expression, imprinting, maternal disomy, Prader-Willi syndrome

\section{INTRODUCTION}

Genetic disorders such as Angelman syndrome, Prader-Willi syndrome, Beckwith-Wiedemann syndrome, and several pediatric cancers are caused by genetic imprinting or an epigenetic process with non-Mendelian inheritance. ${ }^{1-2}$ Prader-Willi and Angelman syndromes were the first examples in humans of genetic imprinting or the differential expression of genetic information depending on the parent of origin. ${ }^{3-4}$ PWS is caused by deficiencies of the paternal specific human chromosome region $15 q 11-q 13$ by paternal deletion (about $70 \%$ of reported cases), maternal uniparental disomy 15 , or imprinting mutations. ${ }^{2,4-7}$ Conversely, Angelman syndrome, an entirely different clinical syndrome, is usually caused by a maternal deletion of the $15 q 11-q 13$ region and rarely caused by paternal uniparental disomy 15. PWS is characterized by infantile hypotonia, hypogonadism, early onset of childhood obesity, hyperphagia, mental deficiency, and minor anomalies. ${ }^{4,-11}$ PWS is the most common dysmorphic cause of marked obesity in humans. ${ }^{4}$

Several paternally expressed imprinted genes and transcripts have been identified from the $15 q 11-q 13$ region. These include

Division of Genetics, Department of Pediatrics, Vanderbilt University Medical Center, Nashville, Tennessee

Merlin G. Butler, MD, PhD, Chief, Section of Medical Genetics and Molecular Medicine, Children's Mercy Hospital, 2401 Gillham Rond, Kansas City, MO 64108-9898; E-mail: mgbutler@cmh.edu

Submitted for consideration November 17, 1998; accepted for publication February 2, 1999.
ZNF127, NECDIN, SNRPN, PAR5, IPW, and PAR1. ${ }^{1-2,12-15}$ These imprinted genes (SNRPN, IPW, ZNF127, NECDIN) and transcripts (PAR5 and PAR1) are thought to be silent on the maternal chromosome in the normal population and therefore not expressed in PWS subjects lacking this paternal chromosome 15 region. ${ }^{16}$ Gene expression data are lacking from surveys of PWS and control subjects with various genetic alterations of chromosome 15q11-q13. The lack of expression of these gene(s) seems to play a significant role in the causation of PWS. Herein, we report our experience with gene expression studies for the first time using reverse transcription polymerase chain reaction (RT-PCR) in a relatively large survey of previously diagnosed PWS and control subjects. A variety of genetic alterations involving chromosome 15 were present in the PWS or control subjects (e.g., 15q11-q13 deletions, maternal disomy 15, chromosome 15 translocations). The rationale for our study was to determine whether different genetic problems of the $15 q 11-q 13$ region affect the genetic expression of recognized imprinted genes and/or transcripts in this region in PWS or control subjects.

\section{MATERIALS AND METHODS \\ Subjects}

Thirty-eight PWS subjects ( 24 females and 14 males; age range: 1-43 years) were analyzed with various genetic defects of chromosome 15. They were available from a larger group of PWS 
subjects from Vanderbilt University. The PWS subjects were evaluated clinically by one of the authors (MGB) using the diagnostic criteria reported by Holm et al. ${ }^{17}$ and the diagnosis confirmed cytogenetically with fluorescence in situ hybridization (FISH) by routine genetic methods for the SNRPN probe and DNA microsatellites from the chromosome 15q11-q13 region and methylation testing of SNRPN with Southern hybridization or methylation specific PCR. ${ }^{18-22}$ There were no obvious differences in the methylation testing results with either Southern hybridization or methylation PCR of SNRPN in the diagnosis of PWS in our study.

Twenty-one PWS subjects showed the typical 15q11-q13 deletion and only one DNA band of maternal origin of the SNRPN gene by methylation PCR analysis consistent with the diagnosis of PWS. Eleven subjects had normal chromosomes and maternal disomy 15, including one adult female homozygous for 15q1 l-q13 DNA bands, whereas the other maternal disomy 15 subjects were heterozygous (all maternal disomy subjects showed only one DNA band of maternal origin of the SNRPN gene by methylation PCR analysis). Three subjects had translocations involving chromosome 15 [e.g., two translocation patients with a $t(15 ; 15)$ and maternal disomy, and only one DNA band of maternal origin of the SNRPN gene by methylation PCR analysis, and one translocation patient with a $t(15 ; 19)$ karyotype previously reported by Sun et al..$^{23}$ with features consistent with PWS had normal methylation PCR findings (a maternal and a paternal DNA band of the SNRPN gene)]. Two PWS patients with nondeleted imprinting mutations reported previously by Ohta et al. ${ }^{6}$ showed only one DNA band of maternal origin of the SNRPN gene by methylation PCR analysis. The remaining PWS subject had a submicroscopic deletion of chromosome 15 reported previously by Butler et al. ${ }^{19}$ and only one DNA band of maternal origin of the SNRPN gene by methylation PCR analysis. A control sample of ten subjects ( 6 females and 4 males; age range:
3-39 years) was selected from the general genetics clinic population at Vanderbilt University after informed consent. These control individuals were selected because of features suggestive of PWS such as obesity and mental deficiency or having various chromosome 15 abnormalities. For example, one of the control male subjects presented at 10 years of age with autism, severe mental retardation, and an extra bisatellited marker chromosome 15; one female subject at 6 years of age had mild learning impairment and behavior problems and a de novo duplication of the 15q11-q13 region of maternal origin by DNA microsatellite studies; one female subject at 18 years of age presented with features consistent with Angelman syndrome; and one male subject at 4 years of age previously reported by Butler et al. ${ }^{24}$ had a de novo ring chromosome 15 of maternal origin. The remaining control subjects had normal chromosome findings and normal methylation DNA patterns using primer sequences from the SNRPN gene and PCR analysis as described by Kubota et al. ${ }^{21}$ and Muralidhar and Butler. ${ }^{22}$ As stated, several of the remaining control subjects selected for this analysis presented with obesity and mild mental retardation. One control subject was a 39-yearold father of a PWS child with an imprinting mutation reported by Ohta et al. ${ }^{6}$ The father had a normal chromosome study including FISH analysis with the SNRPN probe, normal DNA microsatellite studies of 15q11-q13 loci, and normal methylation PCR analysis with the SNRPN gene.

\section{Molecular genetics}

Total mRNA was extracted from tissue sources from 48 individuals, including 38 PWS and 10 control subjects, using the QuickPrep Micro mRNA purification kit from Pharmacia (Piscataway, NJ). Recently established short-term lymphoblastoid cell lines were analyzed from 43 subjects, short-term fibroblast cultures in three subjects, and autopsy tissue from the cerebellum in one PWS subject and in one control subject. The mRNA

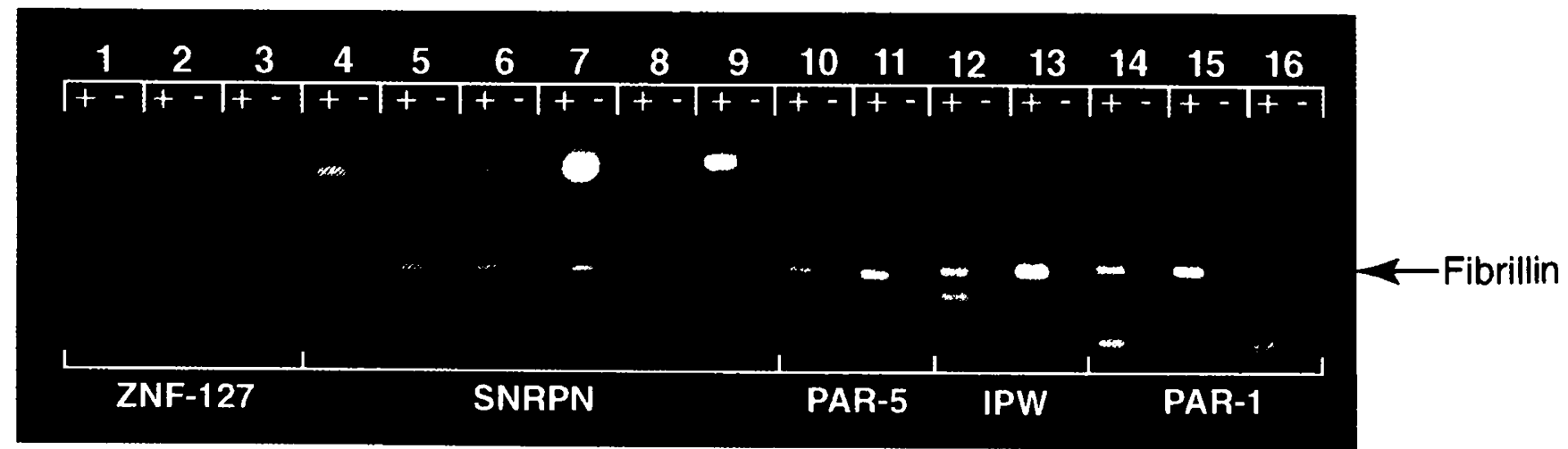

Fig. 1 Representative RT-PCR results using primers from five imprinted genes or transcripts as indicated from the $15 q 11-q 13$ region and fibrillin as an internal control gene from the $15 \mathrm{q} 21$ band in our 38 PWS and 10 control subjects. $(+)$ and $(-)$ for each lane represents RT $+($ cDNA prepared using reverse transcriptase enzyme) and RT $-($ without the enzyme), respectively. Lane 1 = control subject (39-year-old father of a PWS subject with an imprinting mutation) showing lack of expression of ZNF127; lane $2=39$-year-old obese control female subject showing normal expression of ZNF127; lane $3=34$-year-old female with PWS and a 15q11-q13 deletion showing lack of expression of ZNF127; lane $4=4$-year-old male with ring chromosome 15 as a control subject showing normal expression of SNRPN; lane $5=34$-year old male with PWS and a $15 q 11-q 13$ deletion showing lack of expression of SNRPN; lane 6 = 10-year-old female with PWS and a 15q11-q13 deletion showing reduced but detectable expression of SNRPN; lane $7=10$-year-old control male subject with autism and a supernumerary extra bisatellited marker chromosome 15 showing increased expression of SNRPN; lane $8=2$-year-old female with PWS and a t(15;15) with maternal disomy showing normal expression of SNRPN; lane $9=8$-year-old control female subject with learning impairment, behavior problems, and a de novo $15 \mathrm{q} 11-\mathrm{q} 13$ duplication of maternal origin showing increased expression of SNRPN; lane $10=39$-year-old obese control female subject showing normal expression of PAR5; lane $11=34$-year-old female with PWS and a 15q11-q13 deletion showing lack of expression of PAR5; lane 12 = 39-year-old obese control female subject showing normal expression of IPW; lane 13=34-year-old female with PWS and a $15 \mathrm{q} 1 \mathrm{l}$-q 13 deletion showing lack of expression of IPW; lane 14 = 4-year-old male with ring chromosome 15 as a control subject showing normal expression of PAR1; lane $15=17$-year-old male with PWS and a 15q11-q13 deletion showing lack of expression of PAR1; lane 16 = 14-year-old female with PWS and maternal heterodisomy 15 showing normal expression of PAR1. 
Table 1

Primer sequences used to amplify the imprinted and internal control gene(s)

\begin{tabular}{lllcl}
\hline Gene & Primer set & Primer sequence (5'-3') & Size (bp) & Source \\
\hline ZNF127 & Forward & GTTACCCTTCTCTGAGGAC & 615 & Primer data kindly provided \\
& Reverse & CACAGTTTAACAAGTGCAC & & by Dr. R.D. Nicholls; Glenn et al. ${ }^{16}$ \\
SNRPN & Forward (Primer E) & AAGCGGGTTTTGGGTCTGGT & 608 & ${\text { Ozcelik et al. }{ }^{11}}$ \\
& Reverse (Primer L) & ACAAGACGCATTGCAGGGGA & & \\
PAR5 & Forward & CATTGAGATCATACCTGCTCTTAA & \multirow{2}{*}{180} & Sutcliffe et al. ${ }^{25}$ \\
& Reverse & CTAGCAGTGAATCAACTATACTCA & & \\
IPW & Forward & TTATCAGCAAATTCCCAAAACA & 246 & Wevrick et al. $^{26}$ \\
& Reverse & GATATCCCAACATGAGCATTTC & & \\
PAR1 & Forward & CTCAGAGGCTGTAGAACTAAGCAG & \multirow{2}{*}{123} & Sutcliffe et al. ${ }^{25}$ \\
& Reverse & GGTACACTTCCATAGACTTAGGCC & & \\
FIBRILLIN & Forward & CCCAATGTCTGTGGATCACG & \multirow{2}{*}{310} & Pereira et al. ${ }^{23}$ \\
& Reverse & TCCTCCATTGAGACAGCCAC & & \\
\hline
\end{tabular}

(1-2 $\mu \mathrm{g}$ ) was treated with DNase-I. The reverse transcription was performed using Superscript Preamplication System in a 20 ul volume with $100 \mathrm{ng}$ of random hexamers in duplicate with one assay containing Superscript II enzyme $(\mathrm{RT}+)$ and the other assay with no enzyme (RT + ) following the supplier's protocol (Gibco-BRL, Gaithersburg, MD).

PCR was performed with positive and negative controls in a 25 ul volume containing $1 \times$ GeneAmp PCR buffer with $1.5 \mathrm{mM}$ $\mathrm{MgCl}_{2}$ and 2 units of AmpliTaq Gold DNA polymerase (Perkin Elmer, Norwalk, CT), $200 \mu \mathrm{M}$ deoxynucleotide triphosphates, 2 $\mathrm{ul}$ of first strand cDNA, $0.7 \mu \mathrm{M}$ of each respective gene-specific primers, and $0.35 \mu \mathrm{M}$ control primers to amplify the internal control gene (e.g., fibrillin). The polymerase was activated at $94^{\circ} \mathrm{C}$ for 10 minutes, and DNA was amplified for 35 cycles at $94^{\circ} \mathrm{C}$ for
30 seconds, $56^{\circ} \mathrm{C}$ for 30 seconds, and $72^{\circ} \mathrm{C}$ for 30 seconds, and followed by a final extension at $72^{\circ} \mathrm{C}$ for 10 minutes. PCR products were separated using $1.5 \%$ agarose gel in $0.5 \times$ TBE buffer, stained with ethidium bromide, visualized under UV illumination, and photographed. The methodology was similar to that reported by Wevrick and Francke ${ }^{25}$ and lised throughout for both PWS and control subjects. Primer sequences and expected band sizes in base pairs (bp) are shown in Table 1.

\section{RESULTS AND DISCUSSION}

The RT-PCR results are summarized in Table 2. Figure 1 shows representative findings of the imprinted genes and transcripts tested in our PWS and control subjects. Expression of fibrillin, the internal control gene, was detected in all 48 subjects,

Table 2

RT-PCR results from the PWS and control subjects

\begin{tabular}{|c|c|c|c|c|c|}
\hline \multirow[t]{2}{*}{ Subjects } & \multicolumn{5}{|c|}{ Expression of Imprinted Genes and Transcripts Tested } \\
\hline & ZNF127 & SNRPN & PAR5 & $I P W$ & PARI \\
\hline PWS $(n=38)$ & $1 / 38$ & $3 / 38$ & $1 / 38$ & $1 / 38$ & $3 / 38$ \\
\hline $\begin{array}{l}\text { Maternal disomy } 15 \\
\mathrm{n}=13^{\mathrm{a}}\end{array}$ & $0 / 13$ & $1 / 13$ & $0 / 13$ & $0 / 13$ & $2 / 13$ \\
\hline $\begin{array}{l}\text { Deletion } \\
\mathrm{n}=22^{\mathrm{b}}\end{array}$ & $0 / 22$ & $1 / 22$ & $0 / 22$ & $0 / 22$ & $0 / 22$ \\
\hline $\begin{array}{l}\text { Imprinting mutation } \\
\mathrm{n}=2^{\mathrm{c}}\end{array}$ & $0 / 2$ & $0 / 2$ & $0 / 2$ & $0 / 2$ & $0 / 2$ \\
\hline $\begin{array}{l}t(15 ; 19) \\
n=1^{d}\end{array}$ & $1 / 1$ & $1 / 1$ & $1 / 1$ & $1 / 1$ & $1 / 1$ \\
\hline Controls $(\mathrm{n}=10)$ & $9 / 10$ & $10 / 10$ & $10 / 10$ & $10 / 10$ & $10 / 10$ \\
\hline
\end{tabular}

Eleven subjects with normal appearing chromosomes and 2 subjects with a $t(15 ; 15)$.

${ }^{\text {b}}$ Twenty-one subjects with typical $15 q 11-q 13$ deletion and 1 with a submicroscopic deletion reported by Butler et al. ${ }^{19}$

'Both subjects reported by Ohta et al.

dOne subject with a $\mathrm{t}(15 ; 19)$ reported by Sun et al. ${ }^{23}$

PWS, Prader-Willi syndrome. 
indicating that the RT-PCR assay was effective and robust. One PWS subject with a $t(15 ; 19)$ karyotype reported by Sun et al. ${ }^{23}$ showed expression of regions of all five imprinted genes and transcripts. One PWS patient with maternal disomy 15 and normal appearing chromosomes showed a weak but detectable expression signal for PAR1, whereas weak SNRPN expression was detected using primers $E$ and $L$ for exons 4 and $8,{ }^{12}$ in two PWS subjects [one with the typical 15q11-q13 deletion and one with a $t(15 ; 15)$ karyotype and maternal disomy 15 ; see Figure 1]. No difference in gene expression was found by RT-PCR of mRNA isolated from lymphoblasts, fibroblasts, or brain tissue from autopsy specimens when comparing genes and transcripts from the 15q11-q13 region under imprinting control and using the fibrillin gene from chromosome $15 q 21^{26,27}$ as an internal control for our control subjects.

Interestingly, the SNRPN gene expression signal appeared stronger than predicted when comparing fibrillin gene expression for the control subject with the extra marker 15 chromosome and in the control subject with the 15q11-q13 duplication, indicating the presence of extra and active chromosome 15q11-q13 material (see Figure 1). FISH analysis with the SNRPN probe showed the presence of two in situ hybridization signals on the abnormal chromosome 15 indicating that the duplication included the SNRPN locus. The supernumerary marker chromosome 15 in the autistic male involved the 15q11-q13 region of maternal origin. FISH analysis showed the presence of two in situ hybridization signals for SNRPN in the supernumerary marker 15 chromosome confirming the presence of two $15 \mathrm{q} 11-\mathrm{q} 13$ regions and only one signal in each of the two normal appearing chromosome 15s (data not shown). DNA microsatellites from the $15 q 11-q 13$ region showed three DNA bands for the autistic male subject (two from the mother and one from the father), although the control subject with the de novo 15q11-q13 duplication was also of maternal origin by DNA microsatellite studies (data not shown). The explanation for the apparent increased SNRPN gene expression signal in our two control subjects with extra chromosome 15 material of maternal origin is unknown. Possibly, the extra genetic material may have escaped the imprinting process by altering chromatin structure, or the imprinting center is unduplicated and cannot control the expression of excess genetic information in the tissue studied.

The subject with the de novo balanced reciprocal chromosomal translocation of paternal origin involving chromosomes 15 and $19[\mathrm{t}(15 ; 19)(\mathrm{q} 12 ; \mathrm{q} 13.41)]$ reported previously by Sun et al..$^{23}$ had features consistent with PWS. The chromosome breakpoint occurred within the SNRPN gene (between the second and third exons), and genes distal to the breakpoint were translocated to chromosome 19, leaving the imprinting center intact on chromosome 15. Normal expression was observed for the genes in the proximal long-arm of chromosome 15 translocated to chromosome 19, but no total intact SNRPN product was detected in this subject, further lending support to SNRPN gene as a key candidate gene for PWS. ${ }^{23}$

The PWS subjects with expression of the SNRPN gene [one deletion subject and one subject with maternal disomy 15 caused by a $t(15 ; 15)$ ] and PAR1 transcript (one PWS patient with mater- nal disomy 15 and normal appearing chromosomes) was found upon repeated assays, when compared with the fibrillin gene. Repeated assays consisted of re-isolation of mRNA, production of cDNA, and RT-PCR from a new source of cells (e.g., a second lymphoblastoid cell line newly established but at a different time from the same subject). However, only recently established short-term lymphoblastoid cell lines were analyzed in 43 of the 48 subjects, and the gene expression in other tissues from these individuals is unknown. The explanation for the apparent increased SNRPN gene expression signal in our two control subjects with extra chromosome 15 material of maternal origin is unknown. However, the extra genetic material may have escaped the imprinting process because of chromatin structure rearrangement or possibly the instability of an unduplicated imprinting center to control the expression of the excess genetic information. There were no obvious differences identified during the initial clinical evaluation of those PWS patients showing expression of the SNRPN gene or the PAR1 transcript compared with those PWS subjects with no expression detectable for these genes or transcripts. PAR1 is the most distally located imprinted transcript of the five genes or transcripts analyzed in the $15 q 11-q 13$ region. Although the reason(s) for the weak expression of SNRPN gene or PAR1 transcript in these PWS subjects is unknown, possible explanations include relaxation of imprinting of the maternal chromosome 15 or undetected chromosome 15 mosaicism in the deletion PWS subjects. However, we have not found evidence of mosaicism by cytogenetic and molecular genetic studies with increased number of PCR cycles in the maternal disomy 15 or deletion PWS patients analyzed in this study (data not shown).

One control subject with normal appearing chromosomes (father of a PWS child with an imprinting mutation) lacked expression upon repeated assays of ZNF127, which is the most proximally located imprinted gene in the $15 q 11-q 13$ region, but had complete expression of the fibrillin gene detected by RT-PCR (see Figure 1). Normal gene expression was found as expected for the remaining imprinted genes and transcripts studied in this subject. The degree of DNA methylation at several 15q11-q13 loci may play a role in partial expression of the imprinted genes. However, discrepancies in gene expression in the 15q11-q13 region may stimulate further research to unravel the molecular mechanisms involved in imprinting and pathogenesis of PWS.

Partial expression of imprinted DNA bands has been associated with neoplastic conditions such as Wilms tumor, and recently Rogan et al. ${ }^{30}$ reported two unrelated PWS subjects with maternal disomy 15 whose cells expressed imprinted genes or transcripts (i.e., ZNF127, IPW, PAR5). Both patients were diagnosed with PWS during infancy but did not exhibit hyperphagia in childhood. In both patients the imprint switch appeared to occur correctly at SNRPN but did not occur at adjacent loci or was not maintained in either patient. They proposed that relaxation of imprinting could be caused by the failure to reset the imprint in the maternal germ line or to postzygotic gene expression. Therefore, there is evidence of imprinted genes or transcripts that are usually not expressed in PWS to be transcribed in a subset of patients with maternal disomy 15. 
Patients who lack some features of PWS but express imprinted genes may be useful in defining chromosomal segments associated with specific clinical findings. The PWS phenotype appears to be determined both by loss of imprint control function and expression of individual imprinted genes in this chromosome region.

Two of our PWS subjects with maternal disomy 15 showed expression for PAR1, whereas one of these PWS subjects (see Figure 1) with maternal disomy 15 had a $t(15 ; 15)$ karyotype and, with PCR analysis of polymorphic DNA microsatellites from the $15 q 11-q 13$ region (Christian et al. ${ }^{31}$ ), showed only one DNA band consistent with maternal isodisomy 15 (data not shown). In addition, one of our PWS subjects (a 10-yearold female with a 15q11-q13 deletion) showed expression of the SNRPN gene (see Figure 1), whereas the subject with features consistent with PWS and the $t(15 ; 19)$ karyotype, reported by Sun et al., ${ }^{23}$ also showed expression of all or segments of imprinted genes or transcripts in the proximal long arm of chromosome 15 , indicating the presence of a functional imprinting center in this region. Sun et al. ${ }^{23}$ did report that this patient lacked expression of the entire SNRPN gene because the translocation breakpoint occurred between the second and third exons of the SNRPN gene. Based on physical examination and historical data available during the clinical evaluations of the PWS subjects in this study, no obvious recognizable differences were noted among those subjects showing expression of some of the genes or transcripts in the 15q11-q13 region and those without expression. Additional clinical testing is underway to identify whether subtle differences do exist in these subjects or to identify whether partial expression of imprinted loci in the $15 \mathrm{q} 11-\mathrm{q} 13$ region may result in milder phenotypes in PWS patients.

The timing, tissue source, and other unknown factors relating to partial expression of genes that are thought to be imprinted may play a role in the clinical variability seen among subjects with PWS and other known syndromes with imprinting. Gene expression studies may allow for a better understanding of molecular mechanisms in PWS and other abnormalities of proximal chromosome 15q.

\section{Acknowledgments}

We thank Dr. Robert D. Nicholls and Dr. Jamie Gabriel for their helpful suggestions and assistance. This research was partially supported by a grant from the National Institutes of Health (HD30329). We acknowledge the Brain and Tissue Banks for Developmental Disorders from the University of Maryland and University of Miami for supplying autopsy samples.

\section{References}

1. Saitoh S, Buiting K, Rogan PK, Buxton JL, Driscoll DJ, Arnemann J, Konig R, Malcolm S, Horsthemke B, Nicholls RD. Minimal definition of the imprinting center and fixation of a chromosome 15q11-q13 epigenotype by imprinting mutations. Proc Natl Acad Sci USA 1996;93:7811-7815.

2. Nicholls RD, Saitoh S, Horsthemke B. Imprinting in Prader-Willi and Angelman syndromes. Trends Genet 1998;14:194-200.

3. Nicholls RD, Knoll JHM, Butler MG, Karam S, Lalande M. Genetic imprinting suggested by material heterodisomy in non-deletion Prader-Willi syndrome. Nature 1989;342:281-285.

4. Butler MG. Prader-Willi syndrome: Current understanding of cause and diagno- sis. Am I Med Genet 1990;35:319-332.

5. Mascari MJ, Gottlieb W, Rogan PK, Butler MG, Waller DA, Armour JAL, Jeffreys AJ, Ladda RL, Nicholls RD. The frequency of uniparental disomy in Prader-Will syndrome. Implications for molecular diagnosis. N Engl J Med 1992;326:1599-1607.

6. Ohta T, Gray TA, Rogan PK, Buiting K, Gabriel JM, Saitoh S, Muralidhar B, Bilienska B, Krajewska-Walasek M, Driscoll DJ, Horsthemke B, Butler MG, Nicholls RD. Imprinting mutation mechanisms in Prader-Willi syndrome. Am J Hum Genet 1999;64:397-419.

7. Cassidy SB, Beaudet AL, Knoll JHM, Ledbetter D, Nicholls RD, Schwartz S, Butler MG. Diagnostic testing for Prader-Willi and Angelman syndromes: Report of ASHG/ACMG test and technology transfer committee. Am J Hum Genet 1996; 58:1085-1088.

8. Cassidy SB. Prader-Willi syndrome. Curr Probl Pediatr 1984;14:1-55.

9. Butler MG, Meaney FJ, Palmer CG. Clinical and cytogenetic survey of 39 individuals with Prader-Labhart-Willi syndrome. Am J Med Genet 1986;23:793-809.

10. Butler MG. Prader-Willi Syndrome: A guide for parents and professionals. PraderWilli Perspectives, Roslyn Heights, New York, 1995;4:1-52.

11. Thompson T, Butler MG, MacLean Jr WE, Joseph B. Prader-Willi syndrome: Genetics and behavior. Peabody J Edu 1996;71:187-212.

12. Ozcelik T, Leff S, Robinson W, Donlon T, Lalande M, Sanjines E, Francke U. Small nuclear ribonucleoprotein polypeptide N (SNRPN), an expressed gene in the PraderWilli syndrome critical region. Nature Genet 1992;2:265-269.

13. Sutcliffe JS, Han M, Christian SL, Ledbetter LH. Neuronally-expressed Necdin gene: An imprinted candidate gene in Prader-Willi syndrome. Lancet 1997;350:1520-1521.

14. Jay P, Rougeulle C, Massacrier A, Moncla A, Mattei MG, Malzac M, Roeckel N, Taviaux S, Lefranc IL, Cau P, Berta P, Lalande M, Muscatelli F. The human necdin gene, NDN, is maternally imprinted and located in the Prader-Willi syndrome chromosomal region. Nature Genet 1997;17:357-361.

15. MacDonald HR, Wevrick R. The necdin gene is deleted in Prader-Willi syndrome and is imprinted in human and mouse. Hum Mol Genet 1997;6:1873-1878.

16. Glenn CC, Driscoll DJ, Yang TP, Nicholls RD. Genomic imprinting: Potential function and mechanisms revealed by the Prader-Willi and Angelman syndromes. Mol Hum Reprod 1997;3:321-332.

17. Holm VA, Cassidy SB, Butler MG, Hanchett JM, Greenswag LR, Whitman BY, Greenberg F. Prader-Willi syndrome: Consensus diagnostic criteria. Pediatrics 1993;91:398-402.

18. Mutirangura A, Greenberg F, Butler MG, Malcolm S, Nicholls RD, Chakravarti A, Ledbetter DH. Multiplex PCR of three dinucleotide repeats in the Prader-Willi/Angelman critical region (15q11q13): Molecular diagnosis and mechanism of uniparental disomy. Hum Mol Genet 1993;2:143-151.

19. Butler MG, Christian SL, Kubota T, Ledbetter DH. A 5-year-old white girl with Prader-Willi syndrome and a submicroscopic deletion of chromosome 15q11-q13. Am J Med Genet 1996;65:137-141

20. Butler MG. Molecular diagnosis of Prader-Willi syndrome: Comparison of cytogenetic and molecular genetic data including parent of origin dependent methylation DNA patterns. Am J Med Genet 1996;61:188-190.

21. Kubota T, Das S, Christian SL, Baylin SB, Herman JG, Ledbetter DH. Methylationspecific PCR simplifies imprinting analysis. Nature Genet 1997;16:16-17.

22. Muralidhar B, Butler MG. Methylation PCR analysis of Prader-Willi syndrome, Angelman syndrome and control subjects. Am J Med Genet 1998; 80:263-265.

23. Sun Y, Nicholls RD, Butler MG, Saitoh S, Hainline BE, Palmer CG. Breakage in the SNRPN locus in a balanced $46, \mathrm{XY}, \mathrm{t}(15 ; 19)$ Prader-Willi syndrome patient. Hum Mol Genet 1996; 5:517-524.

24. Butler MG, Fogo AB, Fuchs DA, Collins FS, Dev VG, Phillips JA. Brief clinical report and review: Two patients with ring chromosome 15 syndrome. Am J Med Genet 1988;29:149-154.

25. Wevrick R, Francke U. Diagnostic test for the Prader-Willi syndrome by SNRPN expression in blood. Lancet 1996;348:1068-1069.

26. Pereira L, D'Alessio M, Ramirez F, Lynch JR, Sykes B, Pangilinan T, Bonadio J. Genomic organization of the sequence coding for fibrillin, the defective gene product in Marfan syndrome. Hum Mol Genet 1993;2:961-968.

27. Malcolm S, Donlon DA. Report of the second international workshop on human chromosome 15 mapping. Cytogenet Cell Genet 1994;67:2-14.

28. Sutcliffe JS, Nakao M, Christian S, Orstavik KH, Tommerup N, Ledbetter DH, Beaudet AL. Deletions of a differentially methylated CpG island at the SNRPN gene define a putative imprinting control region. Nature Genet 1994;8:52-58.

29. Wevrick R, Kerns JA, Francke U. Identification of a novel paternally expressed gene in the Prader-Willi syndrome region. Hum Mol Genet 1994;3:1877-1882.

30. Rogan PK, Seip JR, White LM, Wenger SL, Steele MW, Sperling MA, Menon R, Knoll JHM. Relaxation of imprinting in patients with Prader-Willi syndrome. Human Genet 1998;103:694-701.

31. Christian SL, Robinson WP, Huang B, Mutirangura A, Line MR, Nakao M, Surti U, Chakravarti A, Ledbetter DH. Molecular characterization of two proximal deletion breakpoint regions in both Prader-Willi and Angelman syndrome patients. Am J Hum Genet 1995;57:40-48. 